Email: population@pncampus.edu.np eJournal Site: http://ejournals.pncampus.edu.np/ejournals/ajps/

\title{
Community-Based Screening for Hypertension and Diabetes among Adults: Study of Western Nepal
}

\author{
Sharada Sharma \\ Pokhara Nursing Campus, TU Institute of Medicine, Pokhara, Nepal \\ Bobby Thapa \\ Nepalgunj Nursing Campus, TU Institute of Medicine, Nepalgunj, Nepal \\ Corresponding Author \& Email \\ Sharada Sharma; Email: sharada825@gmail.com
}

Article History

Submitted 15 December 2021; Reviewed 26 December 2021; Accepted 05 January 2022 DOI: https://doi.org/10.3126/ajps.v1i1.43595

\section{Copyright Information: \\ Copyright 2022@ The Author(s). \\ The journal is licensed under a \\ Creative Commons Attribution- \\ ShareAlike 4.0 International \\ License. \\ (c) (i) (?) \\ Published by \\ Department of Population Studies \\ Prithvi Narayan Campus \\ Tribhuvan University \\ Pokhara, Nepal}

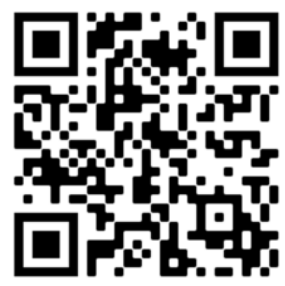

Scan to Access eJournal

\section{Abstract}

Hypertension and diabetes are the major public health problems. The purpose of this study was to determine the prevalence of hypertension and diabetes in western Nepal. Community based cross-sectional screening was done among 142 adult populations aged 20-80 years with blood pressure and blood sugar tests with standard protocol. Adult population was selected as a sample for the study purposively. Among the total adults screened; 73.2 percent were females, 38 percent were the age group 40-59 years with mean standard deviation of age $(50.26 \pm 17.74)$. Hypertension presents in 45.77 percent and diabetes 7.04 percent of the adults. More than half $(55.26 \%)$ of the screened male and 47.11 percent of the screened females were at the hypertension stage II. Hypertension and diabetes is more prevalent in the $\geq 60$ years' adults compared to other age groups. Age and gender were significantly associated with hypertension $\left(\chi^{2}=\right.$ $37.615,7.915) \quad p$ value $<0.05$ respectively. Similarly, there is a significant association between age group and diabetes. Hypertension was found to be more common in comparison to diabetes in all screened adults. Males have a higher prevalence of hypertension and diabetes than females. Age and gender were significantly associated with hypertension. There is a need for early intervention because a remarkably increased number of adults were found to have hypertension.

Keywords: Adult population, community screening, diabetes, hypertension 


\section{Community-Based Screening for Hypertension and Diabetes among Adults}

\section{Introduction}

Hypertension and diabetes are the most common public health problems worldwide. Hypertension is one of the world's major causes of death. Hypertension affects an estimated 1.28 billion persons aged 30 to 79 worldwide, with the majority (two-thirds) residing in low- and middle-income nations. An estimated 46 percent of persons with hypertension are completely ignorant of their illness. Only 42 percent of hypertension individuals receive a diagnosis and treatment. (https://www.who.int/newsroom/fact-sheets/detail/hypertension).

Diabetes affects 537 million individuals worldwide, ranging in age from 20 to 79. By 2030, this number is predicted to rise to 643 million and by 2045, to 783 million. Furthermore, diabetes is linked to a high rate of morbidity and mortality: Over threequarters of diabetic people reside in low- and middle-income nations. Diabetes kills 6.7 million people each year. In South Asia, one out of every eleven persons (90 million) has diabetes. Adults with diabetes are estimated to number 113 million by 2030 and 151 million by 2040 , with more than one in every two adults living with the disease being undiagnosed (International Diabetes Federation, 2021).

In a systematic review among the twenty-three studies in Nepal, hypertension and prehypertension were reported to be 27.3 percent and 35.4 percent, respectively. Hypertension was shown to be present in 28.4 percent, 25.5 percent, and 24.4 percent of urban, suburban, and rural populations, respectively. Furthermore, Males (31.6\%) had higher hypertension rates than females (20.0 percent) and middle-aged people had higher rates of hypertension than younger persons. The study's findings suggest a concerning scenario of hypertension among Nepalese males and middle-aged persons, as well as a concerning condition of prehypertension in rural areas, which affects about 40 percent of the population. (Huang, Guo, Karmacharya, Seeruttun, Xu, \& Hao, 2019).

According to a study conducted among Muslim populations in Manipur, India, the total prevalence of diabetes and hypertension in the entire study group was 16.63 and 18.16 percent, respectively. In 13.8 percent of patients, diabetes and hypertension were found to be co-occurring. The link between diabetes and a number of risk factors, including alcohol consumption and disparities in physical activity, was found to be statistically significant. Diabetes Mellitus is statistically associated with a variety of demographics and age groups. It was also shown that the link between hypertension and various populations and physical activities was statistically significant.

The total diabetes and hypertension prevalence in the study group was 16.63 and 18.16 percent respectively, according to a study conducted among Muslim populations in Manipur, India. Diabetes mellitus and hypertension were found to be co-prevalent in 13.8 percent of people. The relationship between diabetes mellitus and several risk factors, such as alcohol intake and differences in physical activity, was determined to be statistically significant. Diabetes Mellitus has statistically significant associations with various demographics and age categories. It was also shown that the association between hypertension and various populations and physical activities was statistically significant. (Shah, \& Afzal 2013).

Only $50 \%$ of the tested population had previously been diagnosed with high blood pressure, therefore hypertension was found in one-third of them. According to findings from study in the Nepalese community, not only age, body fat, and salt intake, but also potassium, magnesium, and calcium intake play a role in the development of hypertension in Nepalese people (Kawasaki, Itoh \& Ghimire, 1998).

In Nepal, little is understood regarding the prevalence of diabetes and prediabetes, its treatment, and control in different provinces. According to the data from 14 


\section{Community-Based Screening for Hypertension and Diabetes among Adults}

researches with 44,129 participants and 3517 diabetes cases, the prevalence of prediabetes and diabetes is $9.2 \%$ and 8.5 percent, respectively (Shrestha, Mishra, Ghimire, Gyawali \& Mehata, 2020). In another study, diabetes prevalence was found to be 7.5 percent in the screening program, which is significantly lower than the previously reported study in Nepal (Singh, \& Bhattarai, 2003).

In developing countries until the onset of complications, many of those subclinical conditions aren't diagnosed. Thus in nations like Nepal, early diagnosis of these issues is critical. In this regard, a community-based screening was conducted with the aim to identify the hypertension and diabetes prevalence in the adult population.

\section{Methods}

This was the cross sectional community based screening study conducted in ward no.3 B Gaun in Khajura rural municipality, Banke, Nepal. The data was quantitative in nature. Sample was selected purposively following some criteria: consented to participate if they were 20 years old or older and able to join in the screening program. Formal permission was taken from the municipal authority. Initially meetings were conducted to describe the procedure of screening, potential benefits of the program with local leaders and local non-governmental organizations. Survey teams comprised of nursing students and the researchers. Methodology and the procedures of screening were explained to the entire team prior to door-to-door each household survey.

\section{Physiological Measurements}

Using the auscultation method, blood pressure was measured using a random zero mercury sphygmomanometer and a standard cuff $(12 \times 34 \mathrm{~cm})$. The blood pressure was taken while seated peacefully in a chair with feet on the floor and an arm support at the level of the heart. Hypertension was defined as a systolic blood pressure of $140 \mathrm{~mm}$ $\mathrm{Hg}$ or a diastolic blood pressure of $90 \mathrm{~mm} \mathrm{Hg}$, according to the Joint National Committee on Prevention, Detection, Evaluation, and Treatment of High Blood Pressure's Seventh Report. (Whelton, \& Carey, 2017).

A glucometer was used to measure random blood glucose levels. A glucometer determines the concentration of glucose in the blood using electrochemical technology and electrochemical test strips. The measurement of blood glucose was supported by the Khajura rural municipality health department.

Furthermore, health education on prevention and management of hypertension was given. Visual learning aids were disseminated and displayed in public places. Meetings and interaction programs were also conducted with staff of the rural municipality. The researchers and nursing students were responsible for mobilizing the local volunteers, coordinating with local leaders and ensuring that the community was involved. After the screening, referral and counseling was provided for the respondents who have high blood pressure and blood glucose level to the nearby health facility for further investigation, management and treatment.

The authority where the study was conducted gave its approval before collecting data. Permission was sought from the ward's chairperson and informed about the study's purpose. The information gathered was exclusively used for research purposes and was organized according to the study's goals. On the day of collection, the data was doublechecked for accuracy and completeness. Using the computer program SPSS 16 version (Statistical Package for Social Science), data was analyzed and interpreted by descriptive (frequency, percentage, mean, standard deviation) and inferential (chi-squared test) statistics to determine the association between hypertension and diabetes and demographic characteristics. 


\section{Community-Based Screening for Hypertension and Diabetes among Adults}

\section{Results}

In this study data obtained from 142 screened adult populations was analyzed, interpreted and presented in the tables. The study's findings are managed as characteristics of screened adults, prevalence of hypertension and diabetes as well as association with demographic variables.

Table 1

Characteristics of screened Adults

\begin{tabular}{lccc}
\hline Characteristics & Number & \% & Mean \pm SD \\
\hline Gender & 38 & 26.8 & \\
Male & 104 & 73.2 & \\
Female & & & $50.26 \pm 17.74$ \\
Age & 39 & 27.5 & \\
$20-39$ yrs & 54 & 38.0 & \\
$40-59$ yrs & 49 & 34.5 & \\
$\geq 60$ yrs & 65 & 45.77 & \\
Hypertension & 10 & 7.04 & \\
Diabetes & &
\end{tabular}

The table 1 presents that the total screened adults were 142. Among these two third (73.2\%) of the population were female. Although there is no variation in the age group, the mostly screened adults lie in the middle adult age group 40-59 yrs. Almost half $(45.77 \%)$ of the screened adults were hypertensive however; the prevalence of diabetes seems to be very low $(7.04 \%)$.

Table 2

Prevalence of hypertension among screened adults

\begin{tabular}{lccccc}
\hline $\begin{array}{l}\text { Blood } \\
\text { Pressure } \\
\text { Categories }\end{array}$ & $\begin{array}{c}\mathbf{2 0 - 3 9} \text { yrs } \\
\mathbf{n}(\boldsymbol{\%})\end{array}$ & $\begin{array}{c}\mathbf{4 0 - 5 9} \mathbf{\text { yrs }} \\
\mathbf{n}(\boldsymbol{\%})\end{array}$ & $\begin{array}{c}\mathbf{2} \mathbf{6 0} \mathbf{y r s} \\
\mathbf{n}(\boldsymbol{\%})\end{array}$ & $\begin{array}{c}\text { Male } \\
\mathbf{n}(\%)\end{array}$ & $\begin{array}{c}\text { Female } \\
\mathbf{n}(\%)\end{array}$ \\
\hline $\begin{array}{l}\text { Normal } \\
\begin{array}{l}\text { Pre- } \\
\text { hypertension }\end{array}\end{array}$ & $14(51.28)$ & $6(11.11)$ & $6(12.24)$ & $0(0)$ & $32(30.76)$ \\
$\begin{array}{l}\text { Hypertension } \\
\text { stage I }\end{array}$ & $4(10.25)$ & $12(22.22)$ & $7(12.96)$ & $10(26.31)$ & $33(31.73)$ \\
$\begin{array}{l}\text { Hypertension } \\
\text { stage II }\end{array}$ & $1(2.56)$ & $23(42.59)$ & $25(51.02)$ & $21(55.26)$ & $49(47.11)$ \\
\hline
\end{tabular}

Table 2 illustrates the hypertension prevalence among males and females of different age groups. It shows that no males have normal blood pressure whereas only one third $(30.76 \%)$ of the screened females have normal blood pressure. More than half $(55.26 \%)$ of the screened males is at the hypertension stage II and almost half $(47.11 \%)$ of the screened females are also at the hypertension stage II. In the different age groups, hypertension seems to be more prevalent in the age group of $\geq 60$ years compared to other age groups. 
Table 3

Prevalence of diabetes among screened adults

\begin{tabular}{|c|c|c|c|c|c|}
\hline \multirow{2}{*}{$\begin{array}{l}\text { Blood Sugar } \\
\text { Categories }\end{array}$} & \multicolumn{3}{|c|}{ Age Group in Years } & \multicolumn{2}{|c|}{ Gender } \\
\hline & $\begin{array}{l}20-39 \\
\text { n }(\%)\end{array}$ & $\begin{array}{l}40-59 \\
\text { n }(\%)\end{array}$ & $\begin{array}{c}\geq 60 \\
\mathrm{n}(\%)\end{array}$ & $\begin{array}{c}\text { Male n } \\
(\%)\end{array}$ & $\begin{array}{c}\text { Female n } \\
(\%)\end{array}$ \\
\hline Diabetic & $0(0)$ & $3(3.54)$ & $7(14.28)$ & $4(10.52)$ & $6(5.76)$ \\
\hline Non-diabetic & $39(100)$ & $51(94.44)$ & $42(85.71)$ & $34(89.47)$ & $98(94.23)$ \\
\hline
\end{tabular}

Table 3 shows that a few adults are diabetic among the screened population and the prevalence is higher among males as compared to females. Regarding age group, diabetes seems to be more prevalent in old age group i.e. $\geq 60$ years $(14.28 \%)$ whereas among the age group of 20-39 years, no one was found to be diabetic.

\section{Table 4}

Association of hypertension with demographic characteristics of screened adults

\begin{tabular}{|c|c|c|c|c|}
\hline \multirow[t]{2}{*}{ Variables } & \multicolumn{2}{|c|}{ Hypertension } & \multirow[t]{2}{*}{$\chi^{2}$} & \multirow[t]{2}{*}{$p$ value } \\
\hline & $\begin{array}{c}\text { Yes } \\
\mathrm{n}(\%) \\
\end{array}$ & $\begin{array}{c}\text { No } \\
\mathrm{n}(\%) \\
\end{array}$ & & \\
\hline \multicolumn{5}{|c|}{ Age group in } \\
\hline $20-39$ & 34 & 5 & 37.615 & 0.000 \\
\hline $40-59$ & 18 & 36 & & \\
\hline$\geq 60$ & 13 & 36 & & \\
\hline \multicolumn{5}{|l|}{ Gender } \\
\hline Male & 10 & 28 & 7.915 & 0.005 \\
\hline Female & 55 & 49 & & \\
\hline
\end{tabular}

Test statistics: Chi-square test

Significant at $P$ - value $<0.05$

The table 4 revealed that there is a significant association $\left(\chi^{2}=37.615\right)$ between the age group and hypertension at the $\mathrm{p}$ value $<0.000$. Similarly, it also shows a significant association between gender $\left(\chi^{2}=7.915\right)$ and hypertension at the $p$ value $<0.005$.

Table 5

Association of diabetes with demographic characteristics of screened adults

\begin{tabular}{lcccc}
\hline Variables & \multicolumn{2}{c}{ Diabetes } & $\chi^{2}$ & $p$ value \\
\cline { 2 - 3 } & $\begin{array}{c}\text { Yes } \\
\mathrm{n}(\%)\end{array}$ & $\begin{array}{c}\text { No } \\
\mathrm{n}(\%)\end{array}$ & & \\
\hline Age group in Yrs & & & & 0.029 \\
$20-39$ & 0 & 39 & & \\
$40-59$ & 3 & 51 & & \\
$\geq 60$ & 7 & 42 & & 0.064 \\
Gender & & & & \\
Male & 4 & 34 & 0.962 & \\
Female & 6 & 98 & & \\
\hline
\end{tabular}

Test statistics: Chi-square test

Significant at $P$ - value $<0.05$

The table 5 revealed that there is a significant association $\left(\chi^{2}=7.064\right)$ between the age group and diabetes at the $\mathrm{p}$ value $<0.029$. There is no significant association between gender and diabetes among the screened population. 


\section{Community-Based Screening for Hypertension and Diabetes among Adults}

\section{Discussion}

This study is community-based screening that aims to identify hypertension and diabetes prevalence. Findings of the study show that 45.77 percent adults had hypertension. Similar prevalence is observed in the studies done by (Singh \& Bhattarai, 2003; Shrestha, Mishra, Ghimire, Gyawali \& Mehata, 2020; Simeni et.al, 2020; Joshi, et.al, 2012; Al Kibria,et.al, 2018) and markedly higher than the previously reported studies (Shah \& Afzal, 2013; Majumdar, et.al 2014; Sharma, et.al,2013)

Regarding the diabetes prevalence, a current study revealed 7.04 percent adults had diabetes. The overall prevalence of diabetes in the entire population was determined to be 16.63 percent in a study conducted in Manipur, India. (Shah \& Afzal, 2013; Majumdar et.al, 2014). This finding is higher than the current study. Similar findings observed in the study (Simeni et.al, 2020; Sharma, et.al, 2011)

More than half $(55.26 \%)$ of the screened male and 47.11 percent screened female are at the hypertension stage II. In the different age groups, hypertension seems to be more prevalent in the age $\geq 60$ years compared to other age groups. As a result, the study findings highlight the necessity of screening to detect the condition at an earlier age. In a study similar to this one, the hypertension prevalence was shown to be higher in males than females (Yuvaraj, Nagendra Gowda, \& Umakantha, 2010). Another study found no difference in the hypertension prevalence between men and women (Vimala, Ranji, Jyosna, Chandran, Mathews \& Pappachan, 2009).

Rao et al. observed that $38.7 \%$ of people have prehypertension, with 20.2 percent having newly diagnosed hypertension, in a large community-based survey (Rao, Kamath, Shetty, \& Kamath, 2013). The different study's findings are quite different to these. This suggests that screening at a facility rather than in the community may be a more cost-effective choice. However, cost-effectiveness studies are required to demonstrate this. Although rising age, that is, age $>40$ years, has been linked to hypertension in several research (Mahmood, Srivastava, Shrotriya, Shaifali, \& Mishra, 2011; Bansal, Goel, Saxena, Kandpal, Gray, \& Walker, 2012) but the current study indicated a higher prevalence in the age group 30-39 years.

As a result of the study's findings, there is a significant association $\left(\chi^{2}=37.615\right)$ between the age group and hypertension at the $\mathrm{p}$ value $<0.000$. Similarly, it also shows a significant association between gender $\left(\chi^{2}=7.915\right)$ and hypertension at the $\mathrm{p}$ value $<0.005$. The hypertension prevalence increased with age, according to the majority of research. In Manipur India, however, there was a slightly different observation. Since the age range of (40-60) years had the highest diabetes and hypertension prevalence. Age does not appear to play a significant role in the development of hypertension. Chi square shows no significant association with the hypertension prevalence and age (Shah \& Afzal, 2013).

Current study shows that a few adults are diabetic among the screened population and the prevalence is higher among males as compared to females. Regarding age group, diabetes seems to be more prevalent in old age group i.e. $\geq 60$ yrs $(14.28 \%)$ whereas no one was found to be diabetic among the age group of 20-39 yrs. Chi square test shows that age is significantly associated with diabetes prevalence $\left(\chi^{2}=7.064\right)$ at the $\mathrm{p}$ value $<0.029$. There is no significant association between gender and diabetes among the screened population. Likewise, in a research conducted in rural Wardha, the majority of diabetics were between the ages of 50-60 years (Khatib, Quazi, Gaidhane, Waghmare, \& Goyal, 2008). Diabetes prevalence increases with age, according to a prior study, but in the current study diabetes is more common between the ages of $40-59$ years. 


\section{Community-Based Screening for Hypertension and Diabetes among Adults}

\section{Conclusion}

In all screened adult populations, hypertension was shown to be more prevalent than diabetes. Males have a higher prevalence rate than females. More than half of the men who were screened had hypertension stage II. In comparison to other age groups, hypertension appears to be more prevalent in those aged 60 and above. The age group and gender have significant associations with hypertension. Similarly, only a small percentage of adults in the tested population have diabetes, and males have a higher frequency than females. Regarding age groups, diabetes seems to be more prevalent in old age groups. Hypertension was observed in a rather large number of adults, indicating the need for early intervention. The need of adopting effective prevention and control measures is highlighted by the higher prevalence rate.

\section{Acknowledgement}

Authors are grateful to the respondents who agreed to be interviewed, staff of Khajura Rural Municipality and bachelor in nursing science $2^{\text {nd }}$ year students of Nepalgunj Nursing campus for making the screening program successful.

\section{References}

Al Kibria, G. M., Swasey, K., Angela, K. C., Mirbolouk, M., Sakib, M. N., Sharmeen, A., ... \& Stafford, K. A. (2018). Estimated change in prevalence of hypertension in Nepal following application of the 2017 ACC/AHA guideline. JAMA Network Open, 1(3), e180606-e180606. https://doi.org/10.1001/jamanetworkopen.2018.0606

Bansal, S. K., Goel, D., Saxena, V., Kandpal, S. D., Gray, W. K., \& Walker, R. W. (2012). The prevalence of hypertension and hypertension risk factors in a rural Indian community: A prospective door-to-door study. Journal of cardiovascular disease research, 3(2), 117-123.

Huang, Y., Guo, P., Karmacharya, B. M., Seeruttun, S. R., Xu, D. R., \& Hao, Y. (2019). Prevalence of hypertension and prehypertension in Nepal: a systematic review and meta-analysis. Global health research and policy, 4(1), 1-10.

International Diabetes Federation, IDF DIABETES ATLAS tenth edition 2021, 10th edition. Brussels, Belgium 2021 Available at: https://www.diabetesatlas.org

Joshi, S. R., Saboo, B., Vadivale, M., Dani, S. I., Mithal, A., Kaul, U., ... \& Dalal on behalf of the SITE Investigators, J. J. (2012). Prevalence of diagnosed and undiagnosed diabetes and hypertension in India - results from the Screening India's Twin Epidemic (SITE) study. Diabetes technology \& therapeutics, 14(1), $8-15$.

Kawasaki, T., Itoh, K., \& Ghimire, P. (1998). The significance of the daily mineral intake (sodium, potassium, calcium and magnesium) on the genesis of hypertension in Nepal. J Health Sci, 20, 109-18.

Khatib, N. M., Quazi, Z. S., Gaidhane, A. M., Waghmare, T. S., \& Goyal, R. C. (2008). Risk factors of type-2 diabetes mellitus in rural Wardha: A community based study. International Journal of diabetes in developing countries, 28(3), 79.

Mahmood, S. E., Srivastava, A., Shrotriya, V. P., Shaifali, I., \& Mishra, P. (2011). Prevalence and epidemiological correlates of hypertension among labour population. Nat J Community Med, 2(1), 43-48. 


\section{Community-Based Screening for Hypertension and Diabetes among Adults}

Majumdar, A., Chinnakali, P., Vinayagamoorthy, V., Daya, P. A., Shidam, U. G., \& Roy, G. (2014). Opportunistic screening for hypertension and selected cardiovascular risk factors among adults attending a primary health center in Puducherry, India. International journal of preventive medicine, 5(12), 1616.

Rao, C. R., Kamath, V. G., Shetty, A., \& Kamath, A. (2013). High blood pressure prevalence and significant correlates: a quantitative analysis from coastal karnataka, India. International scholarly research notices, 2013. http://dx.doi.org/10.5402/2013/574973

Shah, A., \& Afzal, M. (2013). Prevalence of diabetes and hypertension and association with various risk factors among different Muslim populations of Manipur, India. Journal of Diabetes \& Metabolic Disorders, 12(1), 1-10.

Sharma, S. K., Dhakal, S., Thapa, L., Ghimire, A., Tamrakar, R., Chaudhary, S., ... \& Lamsal, M. (2013). Community-based screening for chronic kidney disease, hypertension and diabetes in Dharan. Journal of Nepal Medical Association, 52(189), 205-212.

Sharma, S. K., Ghimire, A., Radhakrishnan, J., Thapa, L., Shrestha, N. R., Paudel, N., ... \& Brodie, D. (2011). Prevalence of hypertension, obesity, diabetes, and metabolic syndrome in Nepal. International Journal of Hypertension, 2011. https://doi.org/10.4061/2011/821971

Shrestha, N., Mishra, S. R., Ghimire, S., Gyawali, B., \& Mehata, S. (2020). Burden of diabetes and prediabetes in Nepal: A systematic review and metaanalysis. Diabetes Therapy, 11(19), 1935-1946.

Simeni Njonnou, S. R., Boombhi, J., Etoa Etoga, M. C., Tiodoung Timnou, A., Jingi, A. M., Nkem Efon, K., ... \& Sobngwi, E. (2020). Prevalence of diabetes and associated risk factors among a group of prisoners in the Yaoundé central prison. Journal of Diabetes Research, 2020. https://doi.org/10.1155/2020/5016327

Singh, D. L., \& Bhattarai, M. D. (2003). High prevalence of diabetes and impaired fasting glycaemia in urban Nepal. Diabetic medicine, 20(2), 170-171. https://doi.org/10.1046/j.1464-5491.2003.00829_4.x

Vimala, A., Ranji, S. A., Jyosna, M. T., Chandran, V., Mathews, S. R., \& Pappachan, J. M. (2009). The prevalence, risk factors and awareness of hypertension in an urban population of Kerala (South India). Saudi Journal of Kidney Diseases and Transplantation, 20(4), 685.

Whelton, P. K., \& Carey, R. M. (2017). The 2017 clinical practice guideline for high blood pressure. Jama, 318(21), 2073-2074. https://doi.org/10.1001/jama.2017.18209

Yuvaraj, B. Y., Nagendra Gowda, M. R., \& Umakantha, A. G. (2010). Prevalence, awareness, treatment, and control of hypertension in rural areas of Davanagere. Indian journal of community medicine: official publication of Indian Association of Preventive \& Social Medicine, 35(1), 138-141. https://doi.org/10.4103/0970-0218.62578 